\title{
Refurbishment of a Shaking Water Bath
}

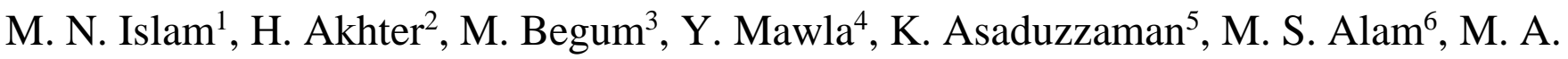
S. Haque ${ }^{7}$, M. Hoq ${ }^{8}$ and M.M.A. Naser Waheed ${ }^{9}$

\author{
${ }^{1,2,3,4}$ Electronics Division, Atomic Energy Centre, Bangladesh Atomic Energy Commission, P.O. Box No. 164, Dhaka, \\ Bangladesh. \\ ${ }^{5,6,7,8}$ Institute of Electronics, Atomic Energy Research Establishment, Bangladesh Atomic Energy, Commission, G.P.O Box \\ 3787, Savar, Dhaka, Bangladesh. \\ ${ }^{9}$ Training Institute, Atomic Energy Research Establishment, Bangladesh Atomic Energy, Commission, G.P.O Box 3787, \\ Savar, Dhaka, Bangladesh.
}

\begin{abstract}
In this article, authors attempt to describe the refurbishment of a temperature controlled shaking water bath. The instrument has mechanical part and electronic part that consists of temperature controller and shaking circuit. Temperature controller circuit has been designed locally and mechanical part and shaking circuit has been re-installed successfully. The circuit has been designed using IC transducers (590KH) which acts high impedances constant current generator $\left(1 \mu \mathrm{A} /{ }^{\circ} \mathrm{K}\right)$ temperature range from $0^{\circ} \mathrm{C}$ above ambient $+100^{\circ} \mathrm{C}$. The instruments have been refurbished for MIID, IFRB,
\end{abstract} AERE, Savar.
Keywords - Process, control variable, controller, servo and transducer.

\section{INTRODUCTION}

Control system is used in all areas of industry. The process may encompass almost any conceivable operation ranging from operation of a machine tool to filling milk bottles. The components comprising a simple control system can be categorized as controller, final actuator or servo, the process and the sensor [1]

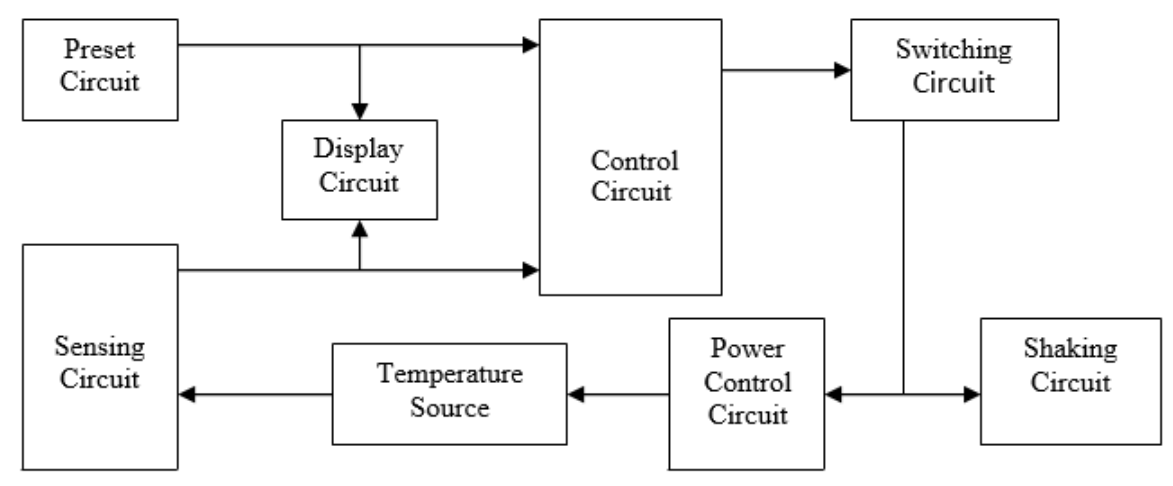

Fig. 1: Shows the Complete Block Diagram of the Refurbished Shaking Water Bath.

A precise temperature control module for shaking water bath has been designed that consists of process means a simple electric heater; control variable is the temperature; on-of controller, triac as a servo and the IC sensor. The module has been designed to meet industrial research, environment, biotech and general laboratory applications which require close temperature control [2]. Temperature range from $00^{\circ} \mathrm{C}$ above ambient $+100^{\circ} \mathrm{C}$, infirmity being \pm 0.30C [3]. Multi-turn potentiometer control for simple, accurate and repeatable operation. Digital panel meter temperature display, simultaneously reads set point and water temperature [4].

\section{PRINCIPLE OF OPERATION}

The operation of the precise temperature control module for the shaking water bath can be illustrated in electric heater operating in a TRIAC circuit [5]. The power supplied until the set point is reached. Delays exist due to the thermal capacity of refectories, the load and the temperature sensor. When the power is switched off when the set point is reached, heat continue to flow resulting in overshot and when the temperature falls through the set point there is a delay before the power is switched on. The delay is known as lag. The relative position of the sensor and load with respect to the heating elements are critical. If the sensor is remote from the heating element, large relativity slow swings of temperature with possible overheating of the load will occur, while it is close to the 
heating element rapid oscillation will occur and load may not reach the required temperature. Oscillation about the set point is inevitable with on-off control since switching occur only at the set point, when full power is applied [6]. temperature at which the power is connected often exists and this may be increased to prevent rapid wear of switch contacts. Proportional action is the basis of continuous control.

A small difference between the set point and the

\section{CIRCUIT DESCRIPTION}

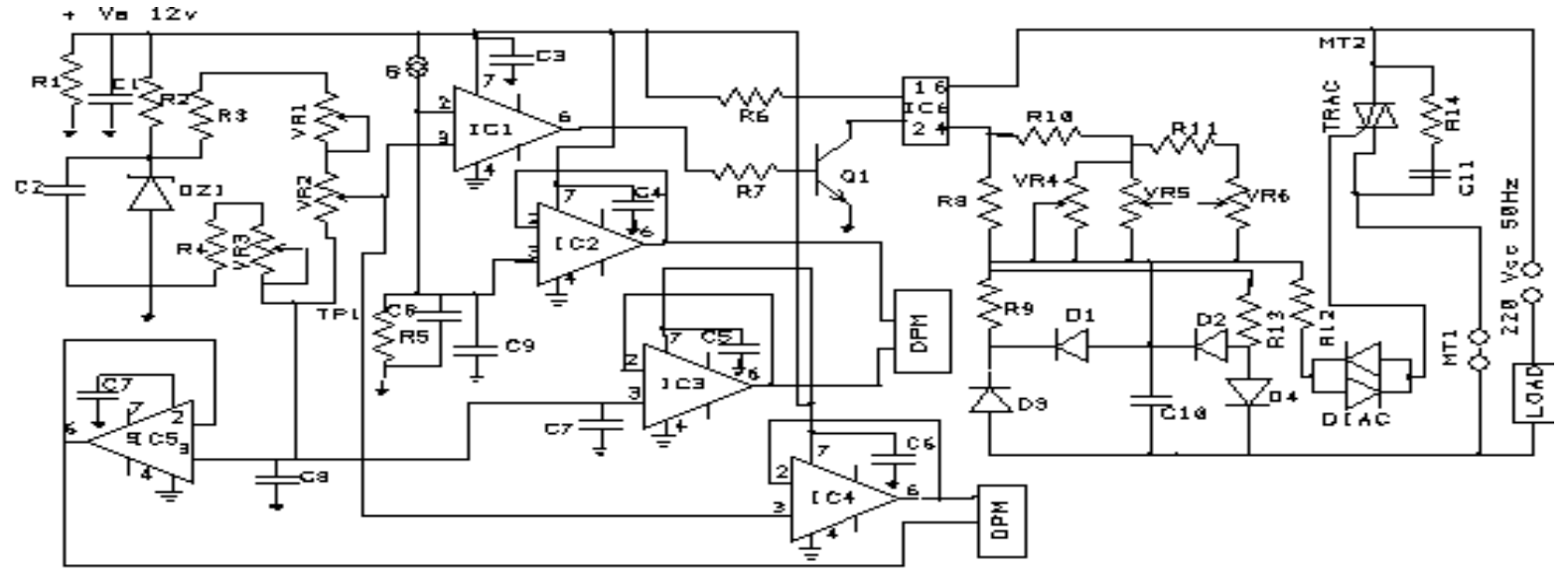

Fig. 2: The Complete circuit diagram of the Water Bath Temperature Control. Module.

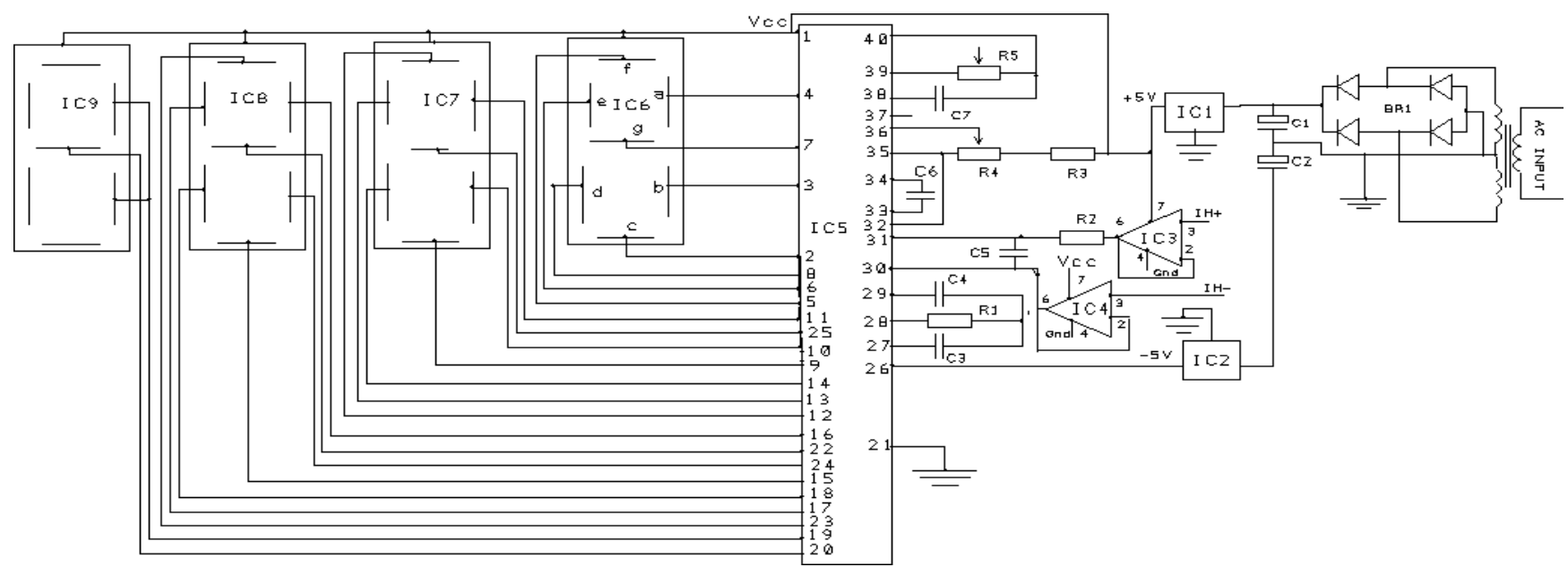

Fig. 3: The Complete circuit diagram of the Digital Panel Meter (DPM).

The power input at any temperature $\theta$ within the proportional band is given by

$W=\frac{\theta-\theta_{1}}{\theta_{2}-\theta_{1}} W_{0}$
$P=\frac{e}{b}$

Where, $\theta_{2}$ is the temperature of the upper limit of the proportional band.

$\theta_{1}$ is the temperature of the lower limit

$\mathrm{W}_{0}$ is the maximum power input at $\theta_{2}$

$\mathrm{e}$ is the error signal and

$\mathrm{b}$ is the constant for the system.

The power can be varied by controlling the mark/space ratio by using thyristors $[7,8]$ to give rapid sequence or phase-shift control. The overshot is reduced by decreasing the power input as the set point reached.

3.1: Power Supply: Power supply circuit comprises step down X-former X1, Bridge Br1 and IC regulator(7812).

3.2: Supply Filter Circuit : The supply voltage is filtered using $\mathrm{R} 1$ and $\mathrm{C} 1$ for ripple free biasing voltage.

3.3: Temperature Preset circuit: Consists of zener diode Dz1, resistor R3, R4 and variable resistor VR1, VR2 and VR3.

3.4:Sensing circuit: The heart of the temperature Controller module is the sensor circuit comprising of sensor $(590 \mathrm{KH}), \mathrm{IC} 1$.

3.5: Switching circuit: The output from the sensor circuit is applied to optocoupler circuit through the switching circuit R7 and Q1. 
3.6: Display circuit: Locally designed DPM has been used as a Display circuit.

3.7: Measure temperature buffer circuit: IC2 stabilize the input from the sensor to the Digital Panel Meter.

3.8: Measure temperature reference circuit: IC3 stabilize the reference signal from the reference circuit to the DPM.

3.9: Set temperature buffer circuit: IC4 is responsible buffering the preset voltage from the temperature preset circuit to the DPM.

3.10: Set temperature reference circuit: IC5 stabilize the preset reference normal.

Table 1: Shows the performance of the Shaking Water Bath

\begin{tabular}{|c|l|l|l|l|l|l|l|}
\hline $\begin{array}{c}\text { Sl. } \\
\text { No. }\end{array}$ & $\begin{array}{c}\text { Normal/ Measure } \\
\text { Temperature } \\
\left({ }^{0} \mathrm{C}\right)\end{array}$ & $\begin{array}{c}\text { Temperature } \\
\left({ }^{\circ} \mathrm{C}\right)\end{array}$ & $\begin{array}{c}\text { Water } \\
\text { Thermometer } \\
\text { Temperature }\left({ }^{\circ} \mathrm{C}\right)\end{array}$ & $\begin{array}{c}\text { Thermal } \\
\text { Inertia } \\
\left({ }^{\circ} \mathrm{C}\right)\end{array}$ & $\begin{array}{c}\text { Rise } \\
\text { Time } \\
(\mathrm{min})\end{array}$ & $\begin{array}{c}\text { Fall } \\
\text { Time } \\
(\mathrm{min})\end{array}$ & $\begin{array}{c}\text { Inertia } \\
\text { Time } \\
(\mathrm{min})\end{array}$ \\
\hline 1 & 27.5 & 37.5 & 42 & 2.50 & 14.48 & 1.14 .7 & 14.02 \\
\hline 2 & 37.5 & 47.5 & 52 & 2.50 & 14.12 & 37 & 9.14 \\
\hline 3 & 47.5 & 57.5 & 62 & 1.80 & 14.05 & 19 & 9.11 \\
\hline 4 & 57.5 & 67.5 & 72 & 1.30 & 17.10 & 14 & 4.25 \\
\hline 5 & 67.5 & 77.5 & 84 & 1.10 & 17.14 & 9 & 4.10 \\
\hline 6 & 77.5 & 87.5 & 90.5 & 0.90 & 17.37 & 7 & 2.03 \\
\hline 7 & 87.5 & 97.5 & 100.5 & 0.60 & 17.57 & 3 & 1.12 \\
\hline
\end{tabular}

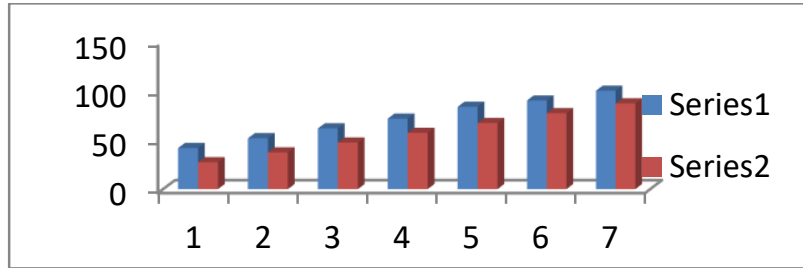

Series1: Thermometer Reading;Series2: Measure Temperature

Fig. 4: Shows the comparison between measure temperature and thermometer reading.

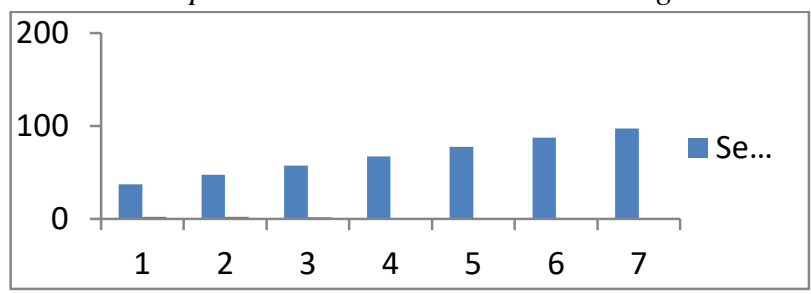

Series1: Set Temperature ; Series2: inertia temperature Fig. 5: Shows the comparison between set temperature and inertia temperature.

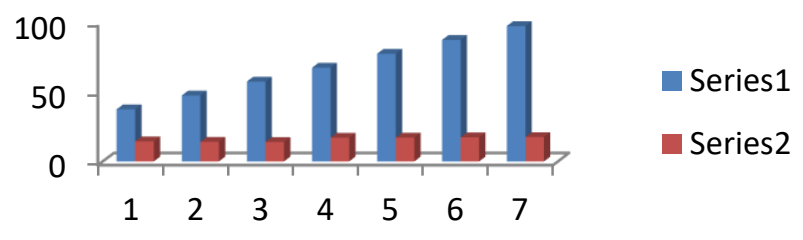

Series1:Set Temperature; Series2:Rise Time

Fig. 6: Shows the comparison between set temperature and rise time.
3.11: Power control circuit: This is the power or heater control circuit of the temperature controller module of the shaking water bath. The main components are R6, IC6 R10 ,R11, VR4, VR5, VR6, R9, D1, D2, D3, D4, C10, R12, DIAC, TRIAC and arc extinguisher by controlling the firing voltage at the DIAC, power can be controlled to the heater.

3.12: Shaking circuit: After checking and performance testing, the original shaking circuit has been reused successfully.

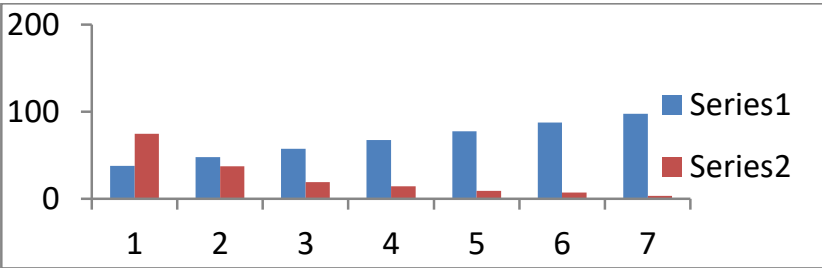

Series1:Set Temperature; Series2:Fall Time

Fig. 7: Shows the comparison between set temperature and fall time.

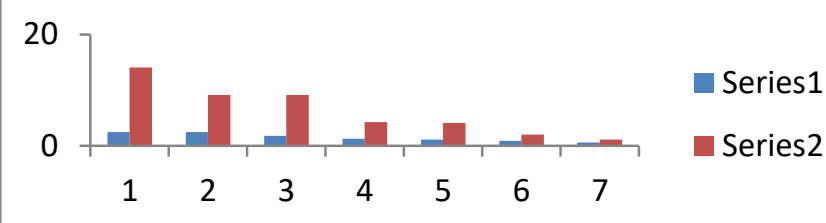

Series1: Thermal Inertia; Series2: Thermal Inertia Time Fig. 8: Shows the comparison between thermal inertia and thermal inertia time.

\section{RESULT AND DISCUSSION}

Fig.4 shows the comparison between the measure value and the thermometer reading. It has been observed that direct thermometer reading is slightly greater than the former one. The cause is due to the different thermal resistance between the device case and transducer container as the process is heat treatment in a water bath. For smooth transmission of heat between them a thermal conductor has been used. The second graph describes the 
thermal inertia at each set point. The highest thermal inertia has been recorded at the lower set point and the lowest at the higher. There exists a inverse relationship between the two temperature. The Fig.6 gives information about the rate of rise of temperature for the designed temperature control module. It has been easily observed that the rise time for first three segments between $30^{\circ} \mathrm{C}$ to $60^{\circ} \mathrm{C}$ is almost equal about 14 mins and different for other four segments between $60^{\circ} \mathrm{C}$ to $100^{\circ} \mathrm{C}$ is almost same 17 mins only. The average rate of rise of temperature for this module is $1.60 \mathrm{~min} /{ }^{\circ} \mathrm{C}$. Likewise, the rate of fall of temperature from thermal inertia to at each set point has been closely observed from the third graph. The fall time of temperature for the first segment is comparatively quite high. This is due to first set point is very close to normal temperature and that's why cooling rate is very slow. Thereafter as the set point are increase and the fall time decrease gradually. The average rate of fall time for this module has been recorded as $1.48 \mathrm{~min} /{ }^{0} \mathrm{C}$. Finally, the fig. 8 describes the relation between the thermal inertia and time duration for the same. It shows that near the normal temperature the thermal inertia as well as time is higher. Thereafter they fall below towards the upper temperature. The average rate of thermal inertia has been observed as $0.62 \mathrm{~min} /{ }^{0} \mathrm{C}$.

\section{CONCLUSION}

The refurbished Shaking Water Bath has been tested repeatedly and its performance was found satisfactory. The data in the table. 1 and the graphical representations show the performance and characteristics of the system. The designed module is cost effective, simple and reliable in operation in the Shaking water Bath.

\section{ACKNOWLEDGEMENTS}

The authors wish to express deep gratitude to Dr. Dilip Kumar Saha, Director, Atomic Energy Centre, Bangladesh Atomic Energy Commission, Dhaka for his support and cooperation in the research.

\section{REFERENCES}

[1] F.F Mazda, Electronics Engineers' Reference Book, 5th Ed., Butterworth \&Co. Ltd., 1983.

[2] Temperature Controller-Wikipedia, Free Encyclopedia, available online 2007.

[3] RS catalogue, RS Components Ltd. July-Oct 1987.

[4] M. Nazrul Islam, Kh Assaduzzaman and M. M. Abu Naser Waheed, Design and Development of a low cost Digital Panel Meter, J. of the Bd. Electron. Soc., Vol. 5(1), June 2005.

[5] M. Nazrul Islam, Kh. Asaduzzaman, Mahbubul Hoq and M.M. Abu Naser Waheed, Design and Performance Study of a Precise Temperature
Control Module, Int. J. of Sys. Signal Control and Engg. Appl., Vol. 5(1), pp.1-4, 2012.

[6] Ronald J Tocci, Fundamental of Electronic Devces, 3rd Ed., A Bell \& Howel Company, Ohio, 1982.

[7] M.C. Sharma, Transgistor and Thyristors Made Easy, 1st Ed., BPB Publocations, Delhi I 10006, 1987.

[8] G.K. Nithal \& Dr. Gupta, Industrial and Power Electronics, 9th Ed., Khanna Publishers, Delhi-1 10006, 2001. 